\title{
Incomplete Reiter's syndrome: clinical comparisons with classical triad
}

\author{
F. C. ARNETT
}

From The Johns Hopkins University and the Good Samaritan Hospital, Maryland, USA

Recently we described 13 patients who appeared to have the typical articular features of Reiter's syndrome (RS) but who did not have clinically obvious genitourinary tract or ocular disease. ${ }^{18} \mathrm{All}$ but one also had HLA-B27. The term 'incomplete Reiter's syndrome' was preliminarily applied to these patients. This paper describes a prospective comparative study of the clinical and laboratory features of 69 patients with either 'classical' or 'incomplete' disease.

\section{Patients and methods}

From 1 September 1974 to 31 March 1978 all patients with a clinical diagnosis of RS seen by me and available for HLA antigen determinations were included in the study. Reiter's disease was diagnosed on clinical features previously reported, ${ }^{18,217,284}$ since criteria for this disorder are as yet unavailable. All patients were entered without knowing whether they were HLA-B27 positive or negative, and none was removed when that information became available. Furthermore, patients were entered regardless of time of disease onset. Many had had relapsing or chronic disease for years. Nevertheless, each patient's history or available medical records had to support RS as the initial diagnosis. Any patient who had psoriasis, inflammatory bowel disease, or an early course typical of ankylosing spondylitis was excluded.

Radiographs of affected joints as well as sacroiliac joints (usually a Ferguson view) were obtained at entry into the study, and the New York radiographic criteria were used to grade sacroiliitis and define spondylitis. Rheumatoid factor determination by latex titration ${ }^{290}$ and complete histocompatibility typing for A and B antigens by the microcytotoxicity test $^{226}$ were carried out for each patient. Urethral cultures for gonococci were obtained only when clinically indicated.

The eight patients from this institution who were originally reported ${ }^{131}$ were included since patients entered into group 1 and 2 were collected over the same time interval.

\section{Results}

After complete clinical evaluation all but one of the 70 patients could be assigned to one of the following disease groups (with respect to completeness for the classical triad).

Group 1-those with the complete triad of nongonococcal urethritis (or cervicitis or vaginitis in women), conjunctivitis (or uveitis), and arthritis (22 patients or $32 \%$ ).

Group 2-those with non-gonococcal urethritis (or cervicitis or vaginitis in women) or conjunctivitis (or uveitis) with arthritis (19 patients or $28 \%$ ).

Group 3-those with arthritis 'alone' who had no prior history or present evidence of obvious urethritis or conjunctivitis but usually presented with some minor features suggestive of RS and were thought on such clinical grounds to have incomplete RS (28 patients or $40 \%$ ).

One additional patient presented with nongonococcal urethritis, conjunctivitis, keratodermia blennorrhagica, painless oral ulcers, circinate balanitis, and nail opacification. He has never developed arthritis and has not been included in the subsequent tabulations, although he does possess B27 and appears to have an incomplete form of RS.

The age of onset (Table 1) was comparable although patients in groups 2 and 3 tended to be slightly older. The disease spanned teenage to late middle life with most presenting in their 20s. Young white males predominated, with only nine females and 14 blacks evenly distributed among the three groups.

Table 1 Demographic features of patients in the three disease groups

\begin{tabular}{llll}
\hline & $\begin{array}{l}\text { Group 1 } \\
(n=22)\end{array}$ & $\begin{array}{l}\text { Group 2 } \\
(n=19)\end{array}$ & $\begin{array}{l}\text { Group 3 } \\
(n=28)\end{array}$ \\
\hline Age at onset & & & \\
$\quad$ Range (yrs) & $16-54$ & $17-59$ & $13-60$ \\
Mean (yrs) & 22.3 & 27.8 & 28.9 \\
Median (yrs) & 21 & 23 & 25 \\
Sex (No. females) & $3(14 \%)$ & $2(11 \%)$ & $4(14 \%)$ \\
Race (No. blacks) & $6(27 \%)$ & $4(21 \%)$ & $4(14 \%)$ \\
\hline
\end{tabular}


The pattern of peripheral joint involvement was virtually identical between the three groups (Table 2). The knees, ankles, and small joints of the feet were most often affected, usually in an asymmetrical fashion. Despite many who complained of 'hip' pain, only one had a frank synovitis of one hip. In the remainder clinical examination showed that sacroiliitis was the probable source of pain. The most commonly affected joints in the upper limbs were small hand joints, again asymmetrically.

The dominance of lower extremity involvement is further highlighted in Table 3, which shows that no patients had an exclusively upper extremity arthritis while in about one-third only the lower limbs were affected. In two-thirds both upper and lower extremity joints were involved. In most, however, few joints were involved, the average number affected varying from $4 \cdot 1$ to $5 \cdot 3$ among the groups. Of interest were four patients in groups 1 and 3 with temporomandibular joint involvement, always unilateral. Sternoclavicular joint swelling and diffuse enlargement of the adjacent clavicle were the presenting features in four patients, none of whom had concomitant axial skeletal complaints or abnormalities.

Thus the arthritis in all three groups was usually oligoarticular, asymmetrical, and predominantly lower extremity, as has been noted in other series.

Pain and tenderness in the plantar calcaneus area occurred frequently in all groups, but was more

Table 2 Comparisons of specific peripheral joints involved among patients in the three disease groups

\begin{tabular}{lccc}
\hline & $\begin{array}{l}\text { Group 1 } \\
(n=22)\end{array}$ & $\begin{array}{l}\text { Group 2 } \\
(n=19)\end{array}$ & $\begin{array}{l}\text { Group 3 } \\
(n=28)\end{array}$ \\
\hline Knees & $16(73 \%)$ & $11(58 \%)$ & $20(71 \%)$ \\
Ankles & $11(50 \%)$ & $9(47 \%)$ & $14(50 \%)$ \\
Small joints of feet & $14(64 \%)$ & $12(63 \%)$ & $18(64 \%)$ \\
Hips & $1(5 \%)$ & $0(0 \%)$ & $0(0 \%)$ \\
Small joints of hands & $8(37 \%)$ & $7(37 \%)$ & $14(50 \%)$ \\
Wrists & $4(18 \%)$ & $5(26 \%)$ & $8(29 \%)$ \\
Elbows & $4(18 \%)$ & $3(16 \%)$ & $8(29 \%)$ \\
Shoulders & $5(23 \%)$ & $3(16 \%)$ & $5(18 \%)$ \\
Temporomandibular & $3(14 \%)$ & $0(0 \%)$ & $1(4 \%)$ \\
Sternoclavicular & $0(0 \%)$ & $3(16 \%)$ & $1(4 \%)$ \\
\hline
\end{tabular}

Table 3 Comparisons of frequencies of upper and lower extremity involvement and number of joints involved among patients in the three disease groups

\begin{tabular}{lccc}
\hline & $\begin{array}{l}\text { Group 1 } \\
(n=22)\end{array}$ & $\begin{array}{l}\text { Group 2 } \\
(n=19)\end{array}$ & $\begin{array}{l}\text { Group 3 } \\
(n=28)\end{array}$ \\
\hline Upper limbs only & 0 & 0 & 0 \\
Lower limbs only & $7(32 \%)$ & $10(53 \%)$ & $10(36 \%)$ \\
Both upper/lower & $15(68 \%)$ & $9(47 \%)$ & $18(64 \%)$ \\
Mean No. joints & 4.4 & $4 \cdot 1$ & $5 \cdot 3$ \\
\hline
\end{tabular}

common in groups 2 and 3 (Table 4). Swelling of the Achilles tendon at its insertion occurred in only two patients, unilaterally in one man in group 1 and bilaterally in a young woman in group 3 . Radiographically demonstrable calcaneal periostitis was far less common than pain and was seen only in those who complained of heel pain.

Diffuse swelling of digits, usually toes, indicative of interphalangeal joint involvement or phalangeal periostitis, or both, was present in half of the patients in all three groups (Table 4). This phenomenon was spotty, asymmetrical, and independent of adjacent nail involvement, unlike what may occur in psoriatic arthritis.

Incapacitating heel pain and painfully swollen toes were the only peripheral articular complaints in three patients in group 2, two of whom had antecedent nongonococcal urethritis and one had prostatitis. In addition, one had concomitant sternoclavicular arthritis and keratodermia, while another had accompanying opacification of one toe nail. Similarly, in group 3 there were three patients with only heel and toe involvement, two of whom had concomitant sacroiliac disease and another nail disease of several fingers. These patients had seen many physicians and received many incorrect diagnoses. One had had surgical biopsies of a? sacroiliac joint and Achilles tendon with the findings of chronic inflammation. All were subsequently found to have HLA-B27.

Inflammatory disease of the spine was more commonly detected clinically than radiographically. Low back pain or stiffness, or both (Table 5), was a frequent complaint in all groups $(53-68 \%)$ and could usually be localised to the sacroiliac joints on

Table 4 Comparisons of frequencies of heel involvement and sausage digits among patients in the three disease groups

\begin{tabular}{lccr}
\hline & $\begin{array}{l}\text { Group I } \\
(n=22)\end{array}$ & $\begin{array}{l}\text { Group 2 } \\
(n=19)\end{array}$ & $\begin{array}{l}\text { Group 3 } \\
(n=28)\end{array}$ \\
\hline Heel pain & $10(45 \%)$ & $12(63 \%)$ & $20(71 \%)$ \\
Periostitis (heel) & $3(14 \%)$ & $0(0 \%)$ & $8(29 \%)$ \\
Sausage digits & $11(50 \%)$ & $11(58 \%)$ & $14(50 \%)$ \\
\hline
\end{tabular}

Table 5 Comparisons of frequency of axial skeletal involvement among patients in the three disease groups

\begin{tabular}{lccc}
\hline & $\begin{array}{l}\text { Group I } \\
(n=22)\end{array}$ & $\begin{array}{l}\text { Group 2 } \\
(n=19)\end{array}$ & $\begin{array}{l}\text { Group 3 } \\
(n=28)\end{array}$ \\
\hline Low back pain & $15(68 \%)$ & $10(53 \%)$ & $17(61 \%)$ \\
Sacroiliitis alone & $3(14 \%)$ & $1(5 \%)$ & $8(29 \%)$ \\
Spondylitis & $3(14 \%)$ & $0(0 \%)$ & $2(7 \%)$ \\
Cervical pain & $0(0 \%)$ & $3(16 \%)$ & $1(4 \%)$ \\
\hline
\end{tabular}

*Excluding those with spondylitis. 
physical examination. However, radiographic evidence of grade 2-4 sacroiliitis alone was found in only $14 \%$ of those with the complete triad (group 1) and $5 \%$ of those with two features of the triad (group 2). The incidence of grade 2-4 sacroiliitis was higher in patients with arthritis 'alone' $(29 \%)$. Bilaterally of $x$-ray lesions was the rule, and the degree of sclerosis and fusion was equal between each sacroiliac joint. Unilateral sacroiliitis occurred only in one patient in each of the three groups. None had asymptomatic sacroiliitis. An additional $14 \%$ of patients in group 1 and $7 \%$ in group 3 had clinical and radiographic evidence of extrapelvic involvement of the spine with loss of lumbar lordosis and mobility, abnormal chest expansion, vertebral body squaring, syndesmophyte formation, or apophyseal joint fusion. Whether syndesmophytes were marginal or non-marginal was not assessed in this study.

The incidence of the mucous skin and membrane lesions of RS are shown in Table 6. Although mucocutaneous lesions were more common in group $1(69 \%)$, one or more of these manifestations occurred often in groups $2(42 \%)$ and $3(25 \%)$. Balanitis was the single most common lesion in groups 1 and 2.

Other features are compared in Table 7. Fever of

Table 6 Comparisons of frequencies of mucocutaneous lesions of Reiter's syndrome among patients in the three disease groups

\begin{tabular}{lcll}
\hline & $\begin{array}{l}\text { Group 1 } \\
(n=22)\end{array}$ & $\begin{array}{l}\text { Group 2 } \\
(n=19)\end{array}$ & $\begin{array}{l}\text { Group 3 } \\
(n=28)\end{array}$ \\
\hline Keratodermia & $8(36 \%)$ & $2(11 \%)$ & $6(21 \%)$ \\
Oral ulcers & $8(36 \%)$ & $1(5 \%)$ & $1(4 \%)$ \\
Balanitis* & $11(58 \%)$ & $4(24 \%)$ & $3(13 \%)$ \\
Nail changes & $2(10 \%)$ & $2(11 \%)$ & $5(18 \%)$ \\
Total & $15(69 \%) \dagger$ & $8(42 \%)$ & $7(25 \%)$ \\
\hline
\end{tabular}

*\% of males.

$\dagger \mathrm{P}<0.01$ by $\chi$ analysis with Yates's correction for comparison between groups 1 and 3 .

Table 7 Comparison of other known features of Reiter's syndrome among the three patient groups

\begin{tabular}{|c|c|c|c|}
\hline & $\begin{array}{l}\text { Group } 1 \\
(n=22)\end{array}$ & $\begin{array}{l}\text { Group } 2 \\
(n=19)\end{array}$ & $\begin{array}{l}\text { Group } 3 \\
(n=28)\end{array}$ \\
\hline $\begin{array}{l}\text { Fever }\left(\geqslant 101^{\circ} \mathrm{F}\right) \\
\text { Weight loss }\end{array}$ & $8(36 \%)$ & $8(42 \%)$ & $6(21 \%)$ \\
\hline$(\geqslant 4.5 \mathrm{~kg})$ & $2(10 \%)$ & $5(26 \%)$ & $6(21 \%)$ \\
\hline Dysentery & $2(10 \%)$ & $1(5 \%)$ & $1(4 \%)$ \\
\hline $\begin{array}{l}\text { Uveitis } \\
\text { Cardiac }\end{array}$ & $7(32 \%)$ & $1(5 \%)$ & 0 \\
\hline $\begin{array}{l}\text { Complete AV } \\
\text { block } \\
\text { Aortic }\end{array}$ & $1(5 \%)$ & 0 & 0 \\
\hline $\begin{array}{l}\text { insufficiency } \\
\text { Amyloidosis }\end{array}$ & $\begin{array}{l}1(5 \%) \\
1(5 \%)\end{array}$ & $\begin{array}{l}1(5 \%) \\
0\end{array}$ & $\begin{array}{l}1(4 \%) \\
0\end{array}$ \\
\hline
\end{tabular}

$101^{\circ} \mathrm{F}\left(38^{\circ}{ }^{\circ} \mathrm{C}\right)$ or more was common in all groups, usually at the onset of disease or during flares. Weight loss of $4.5 \mathrm{~kg}$. or more over a 1-3 months' interval during active disease and without other explanation developed in from $10 \%-26 \%$. This series of patients seems to represent the sporadic (possibly venereal) form of disease. An antecedent dysenteric episode occurred in less than $10 \%$, and was never associated with a large-scale epidemic of diarrhoae. None of these patients had stools cultured at the time of the gastrointestianl event, and when seen later for their RS they had no enteric pathogens on culture.

Overt uveitis appeared in $32 \%$ of those with the classical triad and in one patient in group 2 . None occurred in group 3 by definition of that category. While uveitis was episodic and self-limited in most patients, one had chronic ocular inflammation requiring continuous local therapy for six years. Complete heart block requiring a permanent pacemaker occurred in one patient with a 56-year history of relapsing disease and spondylitic involvement (group 2). Lesser degrees of conduction disturbance were not studied by electrocardiographic measurements.

Amyloidosis with nephrotic syndrome has developed in another patient (group 1) after a 27year history of relapsing disease. Spondylitis and aortic insufficiency have also complicated the course of his disease. Aortic insufficiency occurred in one patient in each group. This complication led to prosthetic valve replacement in one (group 1) and contributed to the only death in this series in another (group 3). Both had fully developed spondylitis. A further patient (group 2) was noted to have a diastolic murmur two years before the onset of urethritis and arthritis but remained haemodynamically stable. Whether this presumed regurgitation relates to his $\mathbf{R S}$ is unclear.

Haematological abnormalities in these patients are shown in Table 8. There are no significant differences between the groups. A normocytic, normochromic anaemia was common $(23-48 \%)$ but in most the haematocrit remained about $30 \%$. Leucocytosis of between $10000 / \mathrm{mm}^{3}\left(10 \times 10^{9} / \mathrm{l}\right)$ and $20000 / \mathrm{m}^{3}$ $\left(20 \times 10^{9} / 1\right)$ with an excess of juvenile polymorpholeucocytes was also frequently seen. Thrombocytosis with platelet counts ranging from $400000 / \mathrm{mm}^{3}$ $\left(400 \times 10^{9} / \mathrm{l}\right)$ to $600000 / \mathrm{mm}^{3}\left(600 \times 10^{9} / \mathrm{l}\right)$ was found in $20 \%-38 \%$ of patients who had platelet counts done. Anaemia, leucocytosis, and thrombocytosis were invariably associated with active disease, as was a raised erythrocyte sedimentation rate. There were, however, several patients with intense joint, heel, or back pain, often with swollen joints, whose 
Table 8 Comparisons of laboratory features in the three groups of patients

\begin{tabular}{|c|c|c|c|}
\hline & Group I & Group 2 & Group 3 \\
\hline \multicolumn{4}{|l|}{$\begin{array}{l}\text { Anaemia } \\
\text { (haematocrit } \\
<40 \% \text { males, } \\
<36 \% \text { females) }\end{array}$} \\
\hline $\begin{array}{l}\text { Leucocytosis } \\
(\mathrm{WBC}>10000 / \\
\left.\mathrm{mm}^{3}\right)\end{array}$ & $12 / 21(57 \%)$ & $4 / 17(23 \%)$ & $6 / 26(23 \%)$ \\
\hline \multicolumn{4}{|l|}{$\begin{array}{l}\text { Thrombocytosis } \\
\text { (platelets }\end{array}$} \\
\hline$\left.>400000 / \mathrm{mm}^{3}\right)$ & $4 / 15(27 \%)$ & $5 / 13(38 \%)$ & $4 / 20(20 \%)$ \\
\hline \multicolumn{4}{|l|}{$\begin{array}{l}\text { Raised Wintrobe } \\
\text { sedimentation } \\
\text { rate }(>20 \mathrm{~mm}\end{array}$} \\
\hline $\begin{array}{c}\text { in } 1 \mathrm{~h}) \\
\text { HLA-B27 }\end{array}$ & $\begin{array}{l}18 / 21(86 \%) \\
17 / 22(77 \%)\end{array}$ & $\begin{array}{r}9 / 17(53 \%) \\
13 / 19(68 \%)\end{array}$ & $\begin{array}{l}19 / 26(73 \%) \\
26 / 28(93 \%)\end{array}$ \\
\hline
\end{tabular}

erythrocyte sedimentation rates were consistently normal.

Rheumatoid factor tests were negative in all but two patients. One had RS of 30 years duration (group 1) which had progressed to spondylitis, and 10 years before entry had started an additional seropositive, nodular rheumatoid arthritis with Felty's syndrome. HLA-B27 was present. The other patient (group 1) had a typical onset of classical RS. Within six months he developed typical rheumatoid arthritis with nodules and high titre rheumatoid factor. HLA-B27 was absent in this patient. Urethral and cervical smears were cultured for gonococci in all women and in men with urethritis. All were negative.

The incidence of HLA-B27 (Table 8) was high in all three groups, $77 \%$ in group $1,68 \%$ in group 2 , and $93 \%$ in group 3. Two-thirds of the B27-negative patients carried one of the B loci cross-reacting with B27 instead, as previously reported. ${ }^{17}$

The durations of the disease from the year of onset until the present is shown in Table 9. These calculations do not take account of whether the disease was self-limited, relapsing, or chronic. The interval since onset of disease was at least one year in all patients at the completion of the study, the longest periods being 59 years, 12 years, and 39 years, respectively, for the three groups. Mean and median durations were

Table 9 Comparisons of durations of disease among patients in the three disease groups*

\begin{tabular}{llll}
\hline & $\begin{array}{l}\text { Group I } \\
(n=22)\end{array}$ & $\begin{array}{l}\text { Group 2 } \\
(n=19)\end{array}$ & $\begin{array}{l}\text { Group 3 } \\
(n=28)\end{array}$ \\
\hline Range (yrs) & $1-59$ & $1-12$ & $1-39$ \\
Mean (yrs) & 6.6 & 2.9 & 6.8 \\
Median (yrs) & 2.5 & 2.0 & 3.5 \\
\hline
\end{tabular}

-Interval between year of onset and 31 March 1978, regardless of course. comparable except for a shorter mean duration in $\Rightarrow$ group 2 and a trend for longer duration at mean and median levels for group 3.

A determination of each patient's course was made (Table 10). A self-limited course was defined as active articular disease lasting one year or less, a \ chronic course as arthritis of over one year's ڤ્ duration. Those classified as relapsing had to have $\vec{\circ}$ had at least two episodes with a completely : asymptomatic hiatus of six months or more. The frequency of self-limited disease was comparable between the groups $(32 \%-45 \%)$. Those with the complete triad, however, showed a tendency towards more relapsing disease, and those with both incomplete forms a more chronic picture. The difference between the frequencies of chronic course in groups 1 and 3 was significant $(P=0.05)$.

Of greater interest was the fact that patients in each category did not change their pattern with time. Only two patients (one in each of groups 2 and 3) developed conjunctivitis for the first time one and two years after disease onset. Otherwise those with the complete triad maintained those features with each flare or chronically. Similarly, those in group 8 persisted or relapsed with their initial manifestations Those with arthritis 'alone' (group 3 or incomplets RS) never developed urethritis or conjunctivitis + except for the one patient noted above.

\section{Discussion}

At the present time we feel that there are no real clinical differences between the three groups. Incomplete $\mathrm{RS}$ seems to be the same disease as conventional RS. Further support comes from the incidence of HLA-B27, which is similar among the groups and was ascertained independently of clinical grouping.

Table 10 Comparison of courses of disease in the three groups of patients

\begin{tabular}{llll}
\hline & $\begin{array}{l}\text { Group I } \\
(n=22)\end{array}$ & $\begin{array}{l}\text { Group 2 } \\
(n=19)\end{array}$ & $\begin{array}{l}\text { Group 3 } \\
(n=28)\end{array}$ \\
\hline $\begin{array}{l}\text { Self-limited ( } \leqslant 1 \text { yr) } 10(45 \%) \\
\text { (mean months) }\end{array}$ & $(3)$ & $8(42 \%)$ & $9(32 \%)$ \\
$\begin{array}{l}\text { Relapsing } \\
\text { Chronic ( }>1 \text { yr) }\end{array}$ & $\mathbf{8}(36 \%)$ & $(4)$ & $(7)$ \\
\hline
\end{tabular}

*Chronic arthritis for $2,3,27$, and 30 years.

†Chronic arthritis 1.5 to 5 years (mean 2.7 years, median 2.5 years); two patients entered remission at 2 and 5 years respectively.

†Chronic archritis $>1$ to 22 years (mean 3.6, median 3.5); four patients entered remissions at $1 \cdot 5,1 \cdot 5,2 \cdot 5$, and 4 years, respectively; one patient died at 22 years of severe debilitation and aortic insufficiency.

$\S \mathrm{P}<0.05$ by $\chi^{2}$ analysis with Yates's correction for comparison between groups 1 and 3 . 
The concept of incomplete RS is not new. Paronen's ${ }^{244}$ exquisite review of the literature of postdysenteric RS up to 1948 is worth noting: ' $\ldots$ the triad does not evolve in nearly all cases, but the disease may also occur with two or even one essential symptom. Yet both ocular and urethral lesions seem to occur relatively seldom alone or together as the only sign of the syndrome. On the contrary, joint lesions appear in several series in the majority of cases as the only symptom....' The incidence of arthritis alone in his 334 cases resulting from the epidemic of shigellosis in Finland was $3.5 \%$. The majority of cases $(70 \%)$ exhibited the complete triad. In the American literature, Hollander et al ${ }^{\mathbf{1 5 5}}$ seem to have noted this phenomenon shortly after Bauer and Engleman's report ${ }^{22}$ of the first American case. Numerous subsequent reports have discussed postvenereal and postdysenteric arthritis in the context of incompletely expressed RS. ${ }^{113,119,283}$ The recent association of HLA-B27 with RS has helped to unify many of these reports, and the present study provides further confirmation of the validity of these earlier clinical observations.

A second major question of our study was the relative frequency of presentation of the incomplete syndrome. Our data suggest that less than one-third of patients express the classical triad. Furthermore, $28 \%$ of our patients had only two features and $40 \%$ had arthritis alone. In addition, once the pattern of disease was established patients did not tend to acquire the additional features of urethritis or conjunctivitis at a later time. Thus in most the diagnosis was delayed or incorrect, with resultant inappropriate medical and occasionally even surgical treatment. If these frequencies apply beyond our own study population the vast majority of patients with endemic RS are of the incomplete variety. Certainly, similar studies from other institutions and communities will be needed to verify this 'tip of the iceberg' phenomenon.

In conclusion, it must be stated quite clearly that these data shed no new light on the pathogenetic mechanisms of RS. On clinical grounds incomplete RS seems to be the same disease as complete RS. This finding does not, however, imply that they have the same aetiology. Therefore when disease mechanisms are studied homogeneous patient populations should be used. Until the basic pathogenetic pathways are elucidated it might be better to divide and study separately patients with complete and incomplete RS.

\section{General discussion}

DR. G. R. V. HUGHES: I would like to check on one figure. In the arthritis alone group $90 \%$ were B27positive?

DR. ARNETT: Yes, $93 \%$.

DR. H. OTT: We have studied 25 patients with oligoarticular arthritis. ${ }^{169}$ Nearly half of them had the B27 antigen and their clinical picture was the same as that of Dr. Arnett's patients. But none of our patients had urethritis, mucocutaneous lesions, or keratodermia. There were 14 or 15 patients patients with arthritis only, and we were struck by the fact that the course of their arthritis was very mild.

DR. ARNETT: Some of these cases were mild but we did have a few that were strikingly severe. The one death among them was from aortic regurgitation after 22 years of chronic progressive disease. All his peripheral and axial joints were fused.

DR. J. C. WOODRow: I would take issue with the idea that we are dealing here with an entity. For example, you, Dr. Arnett, have some young children in your group of 'incomplete Reiter's syndrome'. It has been known for a long time that patients with ankylosing spondylitis have a history of previous episodes of peripheral arthropathy-for example, knee or ankle swelling, sometimes going back to childhood. Could some of your patients have had urethritis-that is, a diagnosis of RS - that could have been missed? Then there are patients with a totally lower limb arthropathy or just plantar fasciitis or Achilles tendonitis. These include children as young as 12 years. They were seen in the acute stage, examined carefully for urethritis, and had none. Eventually I have seen two cases of acute synovitis of one hip in adult B27positive patients. One was a man aged 60 . After a severe purulent coryzal infection he developed severe left hip pain with loss of movement. That had settled when I saw him weeks later but he then had severe painful swelling of an ankle. The only clue to the diagnosis was that he was B27-positive. Synovitis of one or both knees occurred in six patients, of the ankles in two, of the interphalangeal joints of the toes in three, and Achilles tendon bursitis and plantar periostitis was a feature in three patients. Metatarsophalangeal joint involvement was relatively uncommon. These joints may be affected in various combinations. Not uncommonly there is a positive family history-for example, there were a brother and sister in their teens, both B27-positive and both with acute lower limb arthropathy. Three others had a parent with spondylitis. So my feeling is that there is such a thing as 'B27 arthropathy' but that one is dealing with a heterogeneous group.

DR. D. A. BREWERTON: I am delighted with the facts and descriptions, but I am horrified by the two titles that have been suggested. 'B27 arthritis' cannot be 
correct because the same features are seem in the absence of B27. Then if we are going to say that arthritis in the absence of urethritis-or any of the other features of RS-is 'incomplete Reiter's' the ophthalmologists might call acute uveitis incomplete Reiter's and the cardiologists could use the same argument for aortitis. It may be that the clinical features Dr. Arnett describes are very similar to those in RS, but when they are clearly not related to urethritis or to enteritis it seems to me totally wrong to classify them with RS, with all that that implies. PROF. A. E. GOOD: I would like to ask Dr. Arnett about his group classified as 'arthritis alone'. A fraction of these patients had mucocutaneous lesions, which some would consider to be at least as specific for RS as conjunctivitis and non-specific urethritis. As a splitter, would he consider creating a fourth groupthose who were truly arthritis alone-and telling us what happened to patients who had mucocutaneous manifestations?

DR. ARNETT: I have not really separated them out. Clinically they did not really differ that much from the others. In reply to Dr. Brewerton, I don't think a cardiologist is going to call aortitis 'ankylosing spondylitis' or 'Reiter's'. Dr. Calin has already done a very nice study showing that idiopathic aortic regurgitation is not B27-related, while B27-positive anterior uveitis is a very common epidemiological entity which is not necessarily related to any arthropathy. 